\title{
Sequence of Fibrinogen Proteolysis and Platelet Release after Intrauterine Infusion of Hypertonic Saline
}

\author{
H. L. Nossel, J. Wasser, K. L. Kaplan, K. S. LaGamma, I. Yudelman, and \\ R. E. CanfiEld, Department of Medicine, College of Physicians \& Surgeons of \\ Columbia University, New York 10032
}

\begin{abstract}
A B S T R A C T Plasma fibrinopeptide B (B $\beta 1-14$ or FPB) immunoreactivity was studied by radioimmunoassay in patients who received intrauterine infusion of hypertonic saline to terminate pregnancy. FPB immunoreactivity increased with thrombin treatment (TIFPB) suggesting the presence of a larger FPBcontaining peptide, since purified FPB is not altered by thrombin, whereas thrombin increases the immunoreactivity of $\mathrm{B} \beta 1-42$ (which includes FPB) 10-fold. TIFPB immunoreactivity in plasma, drawn $4 \mathrm{~h}$ after hypertonic saline infusion eluted from Sephadex G-50 similarly to isolated $B \beta 1-42$. Streptokinase, incubated with normal plasma progressively generated TIFPB immunoreactivity, which showed a major component which eluted from Sephadex G-50 similarly to B $\beta 1-42$. Streptokinase generated TIFPB much more rapidly in reptilase-treated plasma that contains fibrin I, (which still includes FPB), indicating that fibrin I is preferred over fibrinogen as a substrate for plasmin cleavage of arginine $(\mathrm{B} \beta 42)$-alanine $(\mathrm{B} \beta 43)$. Serial studies were then made in 10 patients receiving intrauterine hypertonic saline. Fibrinopeptide A (FPA) levels rose immediately, reached a peak between 1 and $2 \mathrm{~h}$, were declining at $4 \mathrm{~h}$, and were normal at 24 and $48 \mathrm{~h}$. TIFPB levels rose slightly in the $1 \mathrm{st} h$, reached a peak at $4 \mathrm{~h}$, and had returned to base-line values at $24 \mathrm{~h}$. Serum fibrinogen degradation product levels were unchanged at $1 \mathrm{~h}$, reached their highest level at $4 \mathrm{~h}$, and were still markedly elevated at 24 and $48 \mathrm{~h}$. Fibrinogen levels dropped slightly being lowest at 4 and $24 \mathrm{~h}$. Platelet counts declined in parallel with the fibrinogen levels over the first $4 \mathrm{~h}$, but continued to decrease through $48 \mathrm{~h}$. Beta thromboglobulin ( $\beta$ TG) levels generally paralleled FPA levels whereas platelet factor 4 (PF4) levels showed only slight changes. The data indicate that immediately after intrauterine hypertonic saline
\end{abstract}

Dr. Kaplan is a Senior Investigator of the New York Heart Association.

Received for publication 4 June 1979 and in revised form 25 July 1979. infusion thrombin is formed that cleaves FPA from fibrinogen to produce fibrin I and releases $\beta$ TG and PF 4 from platelets. Later plasmin cleaves $\mathrm{B} \beta 1-42$ from fibrin I to produce fragment $X$, which is further degraded to form serum fibrinogen degradation products. This sequence of proteolysis indicates that plasmin action on fibrin I serves as a mechanism that regulates fibrin II formation by removing the $\mathrm{B} \beta$ chain cleavage site, which is required for thrombin action in converting fibrin I to fibrin II.

\section{INTRODUCTION}

The proteolysis of fibrinogen by thrombin and plasmin and the activation of platelets are important in normal hemostasis, in thrombosis and in disseminated intravascular coagulation. Recently assays have been developed that reflect fibrinogen proteolysis and platelet activation and allow study of these processes in vivo. Proteolysis of fibrinogen by thrombin occurs in two stages (1-3). In the first step thrombin cleaves fibrinogen to produce fibrinopeptide $A(F P A)^{1}$ and fibrin I (i.e., fibrinogen lacking FPA but still containing fibrinopeptide $B$ [FPB]) and in the second step it releases $\mathrm{FPB}(\mathrm{B} \beta 1-14)$ from fibrin I to produce fibrin II. Early plasmin action removes two-thirds of the $\mathrm{COOH}$ terminal end of the $\mathrm{A} \alpha$-chain and also the $\mathrm{NH}_{2}$-terminal end of the $B \beta$ chain of fibrinogen. $B \beta 1-42$ is the initial specific product of $\mathrm{B} \beta$ chain proteolysis by plasmin (4-5). The remaining molecule is termed fragment $X$ $(6-8) .^{2}$ Specific cleavage products reflecting platelet

${ }^{1}$ Abbreviations used in this paper: $\beta \mathrm{TG}$, beta thromoglobulin; FDP, fibrinogen degradation products; FPA, fibrinopeptide A; FPB, fibrinopeptide B; PF4, plasma factor 4; TIFPB, thrombin-increasable FPB.

2 The term fragment $X$ was originally used to designate a large molecular weight product of early plasmin proteolysis of fibrinogen. The $\mathrm{NH}_{2}$-terminal portion of the $\mathrm{A} \alpha$ chain is still intact. When fibrin I or fibrin II is the substrate for plasmin action a similar fragment is produced that lacks FPA and may be noncovalently bound in large molecular size polymers. 
activation are not known but two proteins specific to the platelet are secreted from the alpha granules in the energy-dependent platelet release reaction (9-11). These proteins are platelet factor 4 (PF4) and beta thromboglobulin ( $\beta$ TG). Specific assays applicable to clinical blood samples have been developed for FPA (12), PF4 (13-15), and $\beta$ TG $(15,16)$. An assay for FPB (3) in vitro has also been developed and this paper describes the use of this assay to identify a plasminproduced peptide, which includes FPB and is derived from the $\mathrm{NH}_{2}$-terminal end of the $\mathrm{B} \beta$ chain.

Serial changes in the plasma concentration of these peptides were studied in patients during the termination of pregnancy by the intrauterine infusion of hypertonic saline. This widely used method for interrupting pregnancy has been documented to be associated with transient in vivo coagulation as reflected by reduction in fibrinogen, clotting factor levels, and platelet counts, and by elevation of serum fibrin(ogen) degradation product (FDP) levels (17-20). The application of assays for FPA (reflecting thrombin action on fibrinogen), for $\mathrm{NH}_{2}$-terminal $\mathrm{B} \beta$ chain peptide (reflecting plasmin action) and for PF4 and $\beta$ TG (reflecting platelet release) in this syndrome is described in this paper.

\section{METHODS}

Reagents. Native FPA was prepared from fibrinogen (grade L, 95\% clottable, from A. B. Kabi, Stockholm) as described by Blombäck et al. (21). Native FPB and B $\beta 1-42$ were gifts of Dr. Birger Blombäck, Department of Blood Coagulation Research, Karolinska Institutet, Stockholm, Sweden or were isolated in this laboratory. Specific antisera and radiolabeled tyrosinated FPA (22), FPB analogue (3), and PF4 and $\beta$ TG (15) were prepared as described. Human thrombin was the gift of Dr. John Fenton, New York State Public Health Laboratories, Albany, N. Y. Streptokinase was streptodornase-streptokinase from Lederle Laboratories Div., American Cyanamid Co., Pearl River, N. Y. Heparin for in vitro use was obtained from Hynson, Westcott \& Dunning, Inc., Baltimore, Md. Ovalbumin was obtained from ICN Nutritional Biochemicals, Cleveland, Ohio, and charcoal (Norit A) from Amend Drug and Chemical Co., Irvington, N. J. Anhydrous denatured ethanol (Fisher Scientific Co., Pittsburgh, $\mathrm{Pa}$.) was used to precipitate fibrinogen from plasma samples. Bentonite was also obtained from Fisher Scientific Co. and protamine sulfate was obtained from Eli Lilly \& Co., Indianapolis, Ind. Sephadex G-50 (superfine) was obtained from Pharmacia Fine Chemicals, Inc., Piscataway, N. J., adenosine from ICN Nutritional Biochemicals, and theophylline from Sigma Chemical Co., St. Louis, Mo. Reptilase was a purified fraction, the gift of Dr. Kurt Stocker, Pentapharm, Zurich, Switzerland.

Patients. The patients involved in this study had all been scheduled for abortion and had provided informed consent to participate in the study. The patients' ages ranged from 19 to $41 \mathrm{yr}$ with a mean of $22 \mathrm{yr}$ and the estimated duration of gestation ranged from 10 to $18 \mathrm{wk}$ with a mean of $16 \mathrm{wk} .200$ $\mathrm{ml}$ of sterile sodium chloride $(20 \%)$ was injected into the uterine cavity over a 2 - to 3 -min period by the patient's obstetrician. All patients aborted within $48 \mathrm{~h}$ of injection of the saline. No patient experienced excess local or any generalized bleeding, fever, tachycardia, or hypotension.

Blood collection and processing. Blood samples were collected from the antecubital veins of patients via 19-gauge needles. To insure that blood flow was free the time between the initial entry of the blood into the syringe and its mixture with the anticoagulant solution was recorded with a stop watch. In all instances the time period was $45 \mathrm{~s}$ or less. Blood for FPA and FPB assays was mixed with one-tenth volume heparin $(1,500 \mathrm{U} / \mathrm{ml})$ and Trasylol $(1,000 \mathrm{U} / \mathrm{ml}$; FBA Pharmaceuticals, Inc., New York). For the FPA assays the blood was processed and assayed as described (12). The rate of FPA generation in vitro was measured as described (23). For the FPB assays the plasma was precipitated with ethanol as described for the FPA assay (12). The plasma was precipitated with ethanol within $30 \mathrm{~min}$ of blood collection and no tests were made on plasma samples that had been stored frozen. Prompt processing of plasma for the FPB assays is necessary because thrombin-increasable FPB (TIFPB) immunoreactivity is generated in vitro during storage in the frozen state even at $-90^{\circ} \mathrm{C}$ despite the presence of protease inhibitors. After precipitation with ethanol and reconstitution with distilled water the plasma extracts were dialyzed for $48 \mathrm{~h}$ and the dialysates were tested for FPB immunoreactivity before and after treatment with thrombin $\left(10 \mathrm{U} / \mathrm{ml}\right.$ for $1 \mathrm{~h}$ at $\left.37^{\circ} \mathrm{C}\right)$ and the results were corrected for incomplete recovery on dialysis to obtain the plasma values. In additional experiments the dialysis step was omitted. The reconstituted samples now contained $\cong 3 \mathrm{U} / \mathrm{ml}$ heparin, which was neutralized by adding protamine sulfate (final concentration $0.15 \mathrm{mg} / \mathrm{ml}$ ). The extracts were tested for FPB immunoreactivity before and after treatment with thrombin. With this procedure recovery of $\mathrm{B} \beta 1-42$ added to blood in vitro averaged $90 \%$ (Table I). Blood for PF4 and $\beta$ TG assays was mixed with one-tenth volume $4 \%$ trisodium citrate that contained $0.01 \mathrm{M}$ adenosine and $0.02 \mathrm{M}$ theophylline $(-0.01 \mathrm{M}$ adenosine $-0.02 \mathrm{M}$ theophylline) and centrifuged for $10 \mathrm{~min}$ at $1,500 \mathrm{~g}$ at room temperature. Platelet-poor plasma was removed and spun at $43,000 \mathrm{~g}$ for $10 \mathrm{~min}$ at $4^{\circ} \mathrm{C}$. The supernatant plasma contained $<250$ platelets/ $\mu \mathrm{l}$ and was stored frozen at $-60^{\circ} \mathrm{C}$ till assay. Blood for fibrinogen and serum FDP measurements was mixed with one-tenth volume $3.8 \%$ trisodium citrate and centrifuged at $1,500 \mathrm{~g}$ for $20 \mathrm{~min}$ to deposit the cells. Serum was prepared by clotting the plasma with thrombin as described elsewhere (24).

Assays. FPA was assayed as described (12). FPB immunoreactivity was assayed as described (3) using similar assay volumes and preincubation as for the FPA assay. Native FPB was used as a standard preparation and antiserum R22 was

TABLE I

Recovery of B Bl-42 Added to Blood

\begin{tabular}{ccc}
\hline \multicolumn{3}{c}{ Concentration } \\
$\begin{array}{ccc}\text { B } \beta 1-42 \text { added } \\
\text { to blood }\end{array}$ & $\begin{array}{c}\text { B } \beta 1-42 \text { recovered } \\
\text { to blood }\end{array}$ & Recovery \\
\hline \multicolumn{3}{c}{ pmol/ml plasma } \\
10.5 & 9.3 & $\%$ \\
21 & 20.4 & 89 \\
42 & 38.7 & 97 \\
60 & 50 & 92 \\
& & 83 \\
\hline
\end{tabular}

The results shown are the mean data from 3 replicate experiments. 
used throughout these studies. PF4 and $\beta$ TG were assayed as described (15). A mol wt of 35,400 was used to calculate the molar concentration of $\beta$ TG and of 30,800 to calculate that of PF4. Fibrinogen levels were measured as described by Ellis and Stransky (25). Serum FDP levels were measured by the tanned erythrocyte hemagglutination inhibition method as described by Merskey et al. (24); the normal level by this technique being up to $1 \mu \mathrm{g} / \mathrm{ml}$. Platelets were counted by a model S plus Coulter Counter (Coulter Electronics Inc., Hialeah, Fla.).

Sephadex G-50 filtration of FPB, B $\beta 1-42$, and extracts of plasma. $5 \mathrm{ml}$ plasma (with heparin and Trasylol), collected from each patient $4 \mathrm{~h}$ after intrauterine injection of hypertonic saline, was dialyzed against $30 \mathrm{ml} 0.05 \mathrm{M} \mathrm{NH}_{4} \mathrm{HCO}_{3}$ containing $50 \mu \mathrm{g} / \mathrm{ml}$ ovalbumin for $48 \mathrm{~h}$. The dialysate was lyophilized and reconstituted in $1.5 \mathrm{ml} 0.15 \mathrm{M}$ Tris-buffered saline $(0.1 \mathrm{M} \mathrm{NaCl}$ and $0.5 \mathrm{M}$ Tris), $\mathrm{pH} 5$, containing $100 \mu \mathrm{g}$ ovalbumin. The sample was applied to a $95 \times 1.2 \mathrm{~cm}$ column packed with Sephadex G-50 (superfine) that had been equilibrated with $0.15 \mathrm{M}$ Tris-buffered saline $\mathrm{pH}$ 5.0, with $0.2 \mathrm{M}$ epsilon aminocaproic acid and $0.01 \%$ ovalbumin. $\left[{ }^{14} \mathrm{C}\right]$ glucose was used as a marker and $1.1 \mathrm{ml}$ fractions were collected. Extracts of plasma samples in which $\mathrm{B} \beta 1-42$ had been generated in vitro by incubation with streptokinase were also filtered over Sephadex G-50 as described for the patients' plasma. Native FPB and B $\beta$ 1-42 were filtered over identical but separately packed columns in the same way. The eluted fractions were tested for FPB immunoreactivity before and after treatment with $1 \mathrm{U}$ thrombin $/ \mathrm{ml}$ for $60 \mathrm{~min}$ at $37^{\circ} \mathrm{C}$.

Generation of $B \beta 1-42$ in vitro. Streptokinase $(1 \mathrm{U} / \mathrm{ml})$ was incubated at $37^{\circ} \mathrm{C}$ with $2 \mathrm{ml}$ citrated plasma. At intervals aliquots of the plasma were removed, Trasylol $(200 \mathrm{U} / \mathrm{ml})$ was added and the samples were precipitated with $50 \%$ ethanol and processed as described (without dialysis) and assayed for FPB immunoreactivity with and without treatment by thrombin. The experiment was then repeated using citrated plasma that had first been incubated with reptilase $(1.7 \mu \mathrm{g} / \mathrm{ml})$ for $10 \mathrm{~min}$ at $27^{\circ} \mathrm{C}$ before incubation with streptokinase. The reptilase had produced a visible clot within $60 \mathrm{~s}$.

\section{RESULTS}

Assay and recovery of B $\beta 1-42$. Measurements of FPA, $\beta$ TG, and PF4 levels in clinical blood samples have been described, but the identification of $B \beta 1-42$ in plasma has not previously been reported. An assay specific for $\mathrm{B} \beta 1-42$ is not available, however, the molecule cross-reacts in the FPB assay. FPB and $\mathrm{B} \beta 1$ 42 react differently in the $\mathrm{FPB}$ assay with antiserum R22 (3). The slope of the inhibition curve for $B \beta 1-42$ is different from that of FPB and the immunoreactivity of $B \beta 1-42$ increases 10 -fold or more after treatment with thrombin, whereas that of FPB is unaltered (Fig. 1). Hence $\mathrm{B} \beta 1-42$ can be distinguished from FPB by an increase in immunoreactivity on treatment with thrombin. Fibrinogen also shows a marked increase in FPB immunoreactivity on treatment with thrombin, so before measuring $B \beta 1-42$ in plasma it is necessary to remove all fibrinogen from the plasma without removing $B \beta 1-42$. This can be done by precipitation of the plasma with ethanol. Precipitation of plasma with $50 \%$ ethanol removes detectable fibrinogen from the plasma without significant precipitation of $\mathrm{B} \beta 1-42$

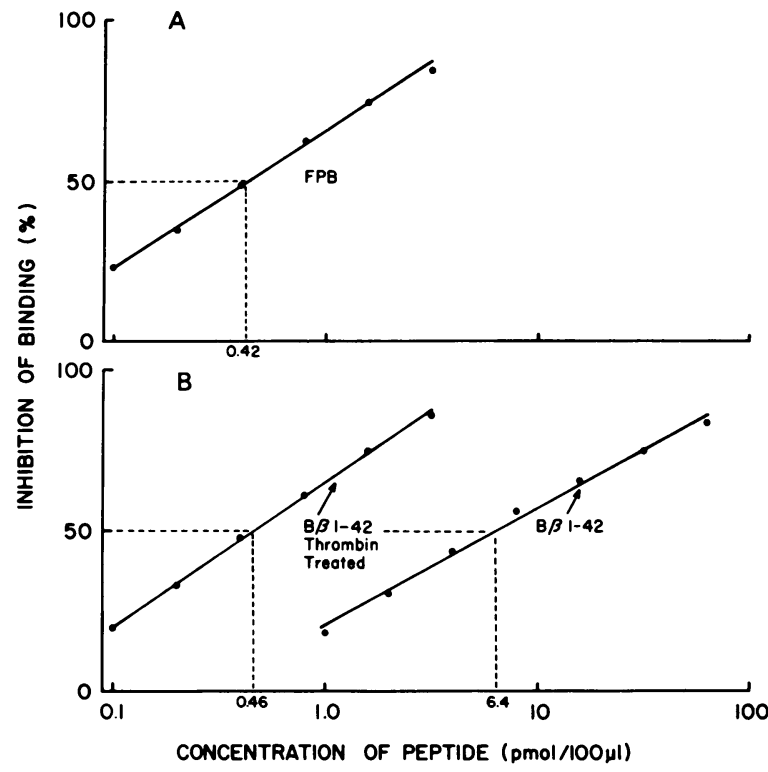

FIGURE 1 Immunoreactivity of FPB, and B $\beta 1-42$ with and without thrombin treatment. Inhibition of binding of ${ }^{125} \mathrm{I}$ labeled tyrosinated FPB analogue by: (A) FPB with or without treatment with thrombin $1 \mathrm{U} / \mathrm{ml}$ for $1 \mathrm{~h}$ at $37^{\circ} \mathrm{C}$ and $(\mathrm{B})$ $\mathrm{B} \beta \mathrm{l}-42$ with or without treatment with thrombin $1 \mathrm{U} / \mathrm{ml}$ for $1 \mathrm{~h}$ at $37^{\circ} \mathrm{C}$.

(Table I). The fibrinogen concentration of the plasma, as indicated by treatment with thrombin and assay of FPA, was $8.2 \times 10^{3} \mathrm{pmol} / \mathrm{ml}$ and was $<0.3 \mathrm{pmol} / \mathrm{ml}$ in the supernatant fluid after precipitation with ethanol.

In vitro generation of TIFPB. When plasma was incubated with streptokinase, progressive generation of TIFPB immunoreactivity occurred and was much more rapid in reptilase-treated plasma in which fibrin I rather than fibrinogen was the substrate for plasmin (Fig. 2). In these experiments an $\cong 10$-fold

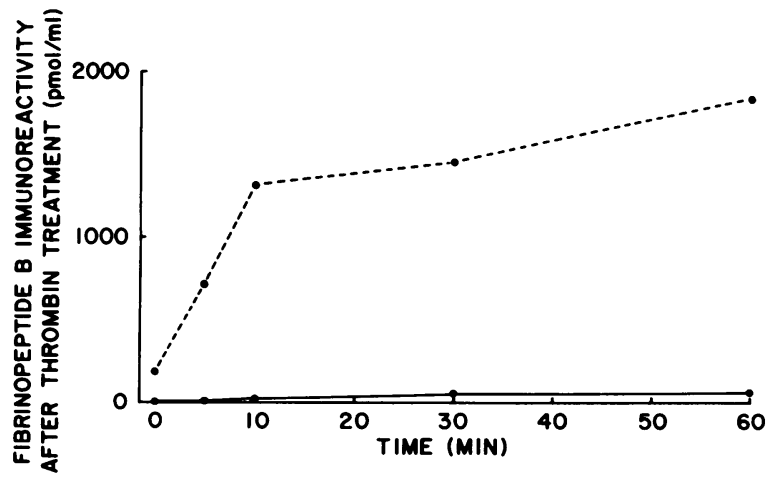

FIGURE 2 The generation of TIFPB in plasma incubated with streptokinase. Streptokinase $(1 \mathrm{U} / \mathrm{ml})$ was incubated with citrated plasma. ( - ) streptokinase added to plasma. (-- -) streptokinase added to plasma first treated with reptilase (FPA content, $19 \mathrm{nmol} / \mathrm{ml}$ ). 
increase in FPB immunoreactivity occurred after thrombin treatment suggesting the presence of FPBcontaining material larger than FPB. In addition the slope of the inhibition curve produced by the non-

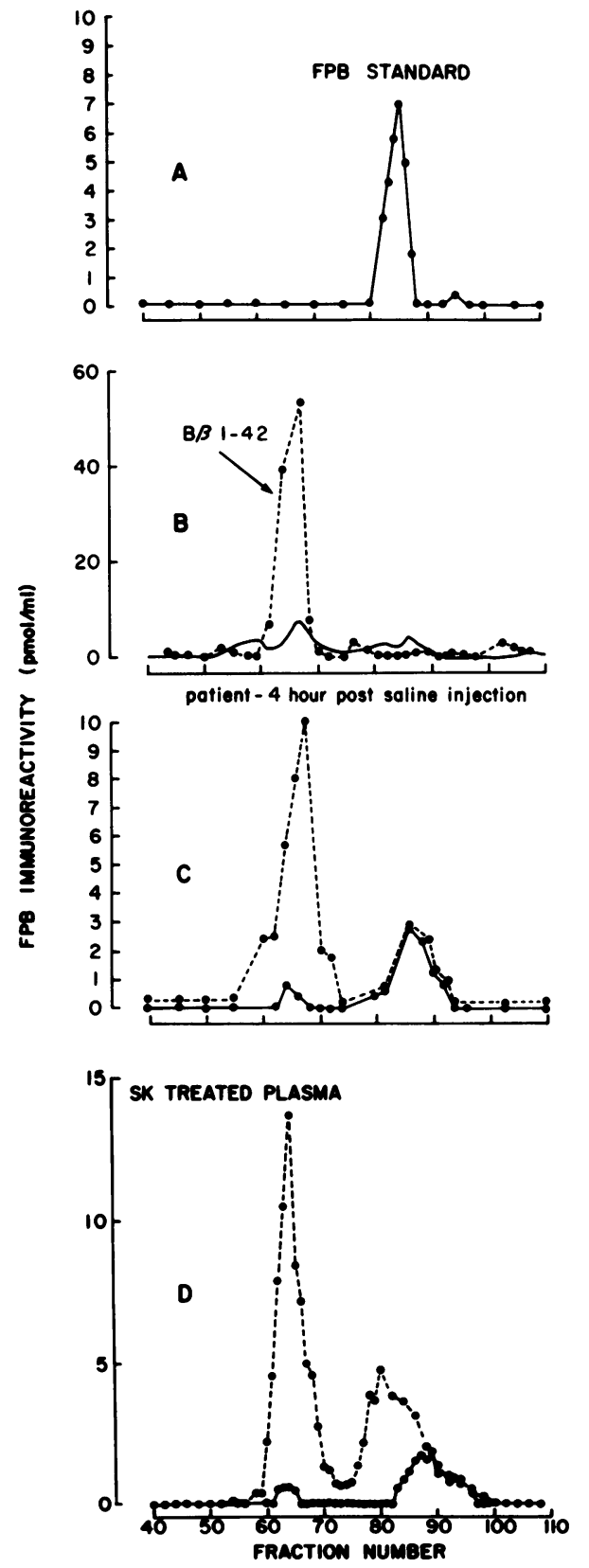

FIGURE 3 Elution patterns from Sephadex G-50 of FPB, $B \beta 1-42,4$-h sample after intrauterine injection of hypertonic saline and plasma incubated with streptokinase in vitro. (A) Native FPB, (B) B $\beta 1-42$, (C) extract of patient plasma drawn $4 \mathrm{~h}$ after intrauterine injection of hypertonic saline, and (D) extract of plasma incubated with streptokinase (SK) $(20 \mathrm{U} / \mathrm{ml})$ for $1 \mathrm{~h}$ at $37^{\circ} \mathrm{C} .1 .1 \mathrm{ml}$ fractions were collected and tested for FPB immunoreactivity before (-) and after treatment with thrombin (- . - -). thrombin-treated samples was different from that of FPB. Gel filtration of streptokinase-treated plasma showed an elution volume for TIFPB immunoreactivity almost identical with that for B $\beta 1-42$ (Fig. $3 \mathrm{~B}$ and D). However, there was also a later eluting peak of FPB immunoreactivity, the upward slope of which also increased on treatment with thrombin and almost certainly represents $B \beta 1-21$ (26). The downward slope probably represents FPB or desarginyl FPB (Fig. 3A and D).

TIFPB immunoreactivity in patient plasma extracts. Extracts of plasma samples taken before and at intervals after intrauterine injection of saline showed a modest increase in FPB immunoreactivity which then decreased to baseline levels (Fig. 4). Thrombin treatment of the extracts increased FPB immunoreactivity markedly resembling the response of isolated $\mathrm{B} \beta 1-42$ (Fig. 4). The slope of the inhibition curve of nonthrombin-treated samples was different from that of FPB. The molecule responsible for the plasma immunoreactivity was further characterized by filtering an extract of the 4-h plasma sample from one patient over Sephadex G-50 and testing the FPB immunoreactivity of the effluent. Two peaks of immunoreactivity were found (Fig. 3C). The earlier eluting peak showed a major increase in immunoreactivity after treatment with thrombin and exhibited the same elution profile as $\mathrm{B} \beta 1-42$. The later peak eluted in the same position as FPB and did not increase in immunoreactivity when treated with thrombin. The plasma extract of a second patient examined in a similar manner gave virtually identical results (data not shown). These findings suggest that most, if not all, the TIFPB immunoreactivity in the patients' plasma represents $\mathrm{B} \beta 1-42$, however, the term TIFPB immunoreactivity is used because $\mathrm{B} \beta 1-21$ also shows a marked increase in immunoreactivity when treated with thrombin (data not shown).

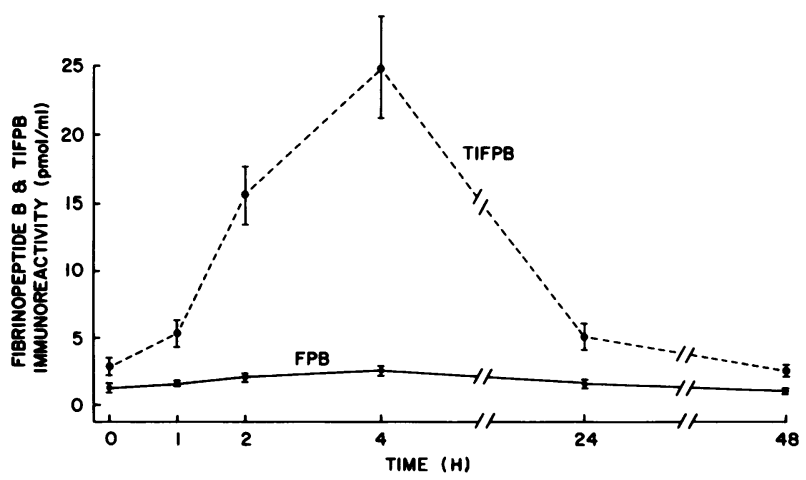

FIGURE 4 Plasma FPB immunoreactivity before and after intrauterine infusion of saline. (-) before thrombin treatment of plasma extracts. (- . - -) after thrombin treatment of plasma extracts. The data shown are the mean $\pm S E M$ in 10 patients. 
Serial studies of in vivo coagulation after saline infusion. Fibrinogen and plasma fibrinopeptide levels, as well as platelet counts and platelet protein concentrations, in the 10 subjects are shown in Fig. 5.
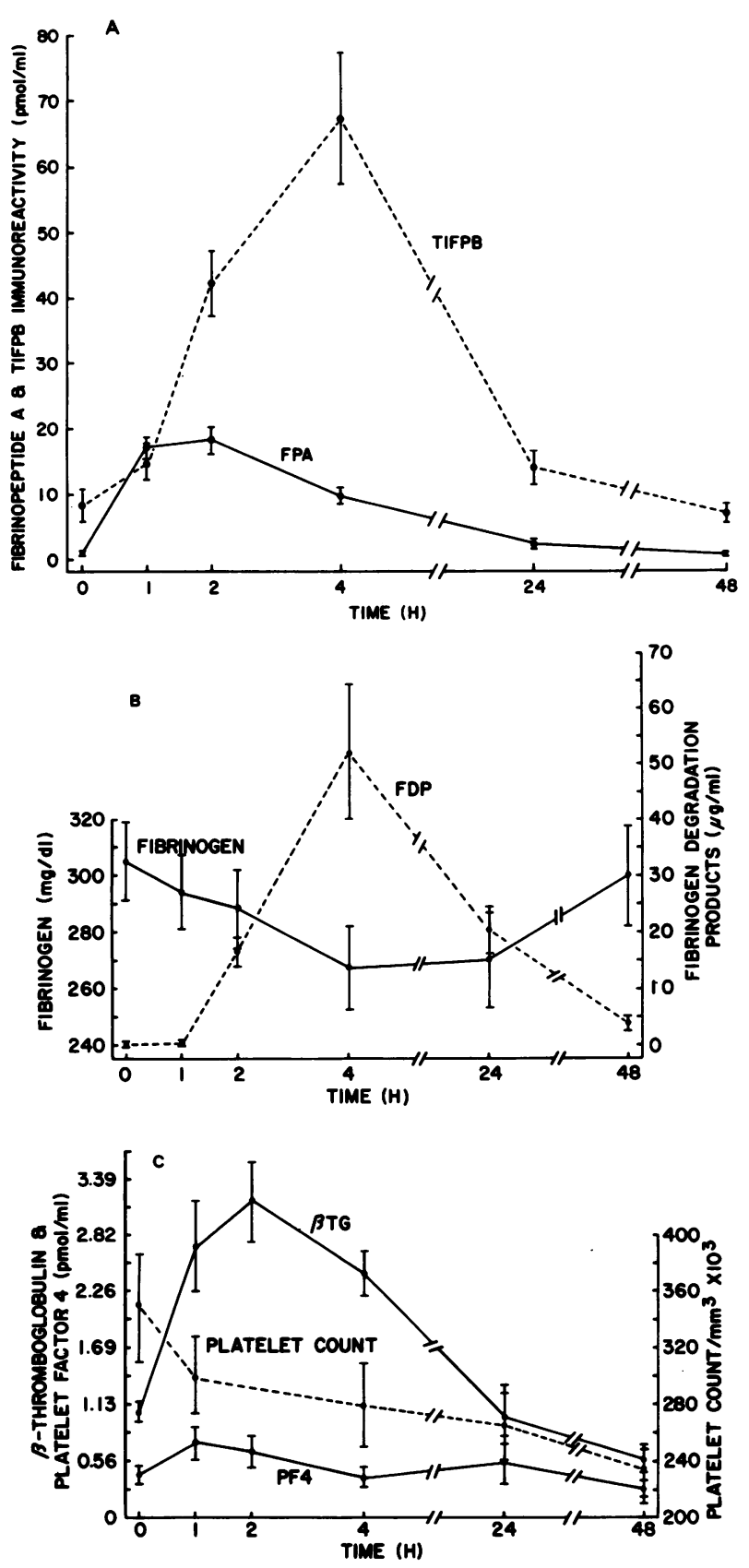

FIGURE 5 Changes in plasma concentrations of FPA, TIFPB, fibrinogen, FDP, PF4, $\beta$ TG, and platelet counts before and $1-48 \mathrm{~h}$ after intrauterine injection of hypertonic saline. (A) FPA and TIFPB levels. The TIFPB levels from Fig. 4 have been divided by 0.37 to correct for incomplete recovery on dialysis. (B) Plasma and serum FDP levels. (C) Platelet counts and plasma PF4 and $\beta$ TG levels. The data are the mean $\pm S E M$ in 10 patients.
FPA levels (5A) were elevated almost 20 -fold at $1 \mathrm{~h}$ and were at approximately the same level at $2 \mathrm{~h}$. They had decreased significantly at $4 \mathrm{~h}$, were only slightly elevated at $24 \mathrm{~h}$, and were normal at $48 \mathrm{~h}$. TIFPB levels (Fig. 5A) showed a slight increase in the 1 st $h$ and then rose more rapidly to reach a peak value at $4 \mathrm{~h}$. At $24 \mathrm{~h}$ the levels were similar to the preinfusion levels and then were slightly lower than preinfusion levels at $48 \mathrm{~h}$ (Fig. 5A). Fibrinogen levels (Fig. 5B) decreased by a mean of $39 \mathrm{mg} / \mathrm{dl}(P=0.007)$ with the lowest levels at 4 and $24 \mathrm{~h}$. By $48 \mathrm{~h}$ preinfusion values had been attained. FDP levels (Fig. 5B) showed no detectable increase at $1 \mathrm{~h}$ but a major increase at $2 \mathrm{~h}$ with the peak level at $4 \mathrm{~h}$. The FDP levels, although decreasing, were still significantly elevated at 24 and $48 \mathrm{~h}$ after saline infusion. Over the first $4 \mathrm{~h}$ the decrease in platelet counts (Fig. 5C) paralleled the decline in fibrinogen levels, but thereafter, instead of returning to the preinfusion level, platelet counts inexplicably continued to decline, reaching their lowest point at $48 \mathrm{~h}$. $\beta$ TG levels (Fig. 5C) rose sharply and had increased about threefold by $1 \mathrm{~h}(P=0.0001)$ with a further increase at $2 \mathrm{~h}$. $\beta$ TG levels had decreased at $4 \mathrm{~h}$, had reached preinfusion levels at $24 \mathrm{~h}$, and were below initial levels at $48 \mathrm{~h}$. PF4 levels (Fig. 5C) showed a similar pattern of changes, but these were much less marked than with $\beta$ TG and were distinctly increased above the base-line values only at $1(P$ $=0.021)$ and $2(P=0.01) \mathrm{h}$ after infusion. The data shown in Fig. 5 represent mean values but the sequence of changes was the same in all patients studied.

To determine whether the increase in FPA levels preceded that of TIFPB levels an additional four patients were studied at intervals during the 1 st $h$ (Fig. 6). FPA levels were elevated immediately (within 3 min of the saline injection) and rose at an almost constant rate (about $0.3 \mathrm{pmol} / \mathrm{ml}$ per min) throughout the $1 \mathrm{st} \mathrm{h}$ to reach a mean of $16 \mathrm{pmol} / \mathrm{ml}$ at $1 \mathrm{~h}$. TIFPB levels were not altered immediately after the infusion of saline, but thereafter rose slightly over the lst h. $\beta$ TG levels showed some fluctuation in the first 30 min but increased in parallel with the FPA levels between 30 and $60 \mathrm{~min}$.

In vitro FPA generation rates were measured in blood samples taken $\mathrm{l} \mathrm{h}$ after injection of saline. In four patients there was no significant FPA generation $(<1 \mathrm{pmol} / \mathrm{ml})$ in vitro and in six patients increased FPA generation (1.1 to $7.0 \mathrm{pmol} / \mathrm{ml}$ ) occurred (Table II).

\section{DISCUSSION}

Our results indicate that TIFPB immunoreactivity reflects the presence of material containing the FPB sequence but larger than the FPB (Fig. 1). When the TIFPB immunoreactivity in patient's blood was further characterized by Sephadex G-50 chromatography it behaved similarly to isolated B $\beta 1-42$ (Fig. 3). However, 


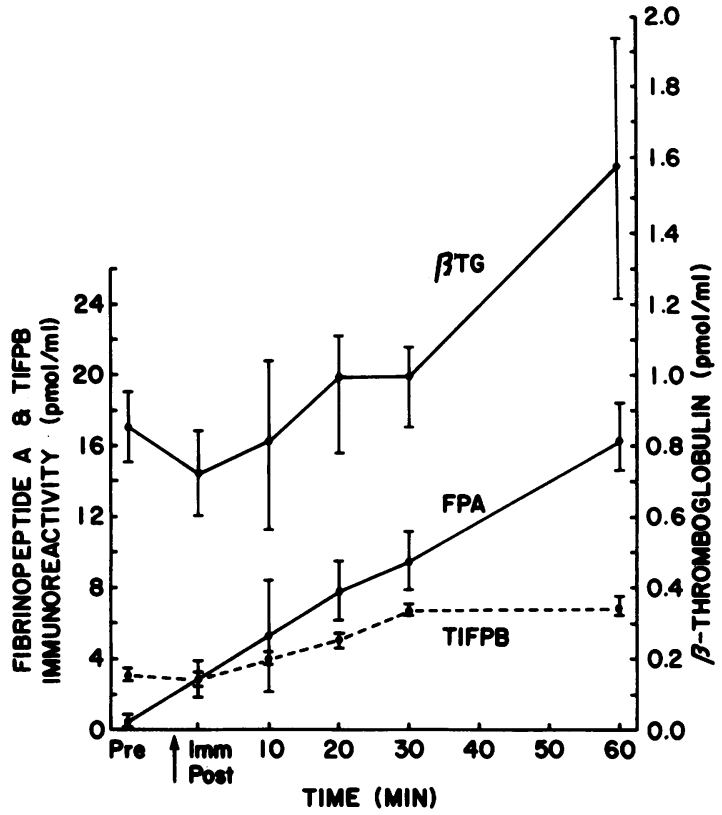

Figure 6 Changes in the lst h after injection of saline. Plasma levels of FPA, TIFPB, and $\beta$ TG are shown. The data are the mean $\pm S E M$ in four patients.

the term TIFPB is preferred to $B \beta 1-42$ because there is as yet no absolute way of distinguishing $\mathrm{B} \beta 1-42$ from $B \beta 1-21$, which also manifests increased immunoreactivity when treated with thrombin. TIFPB immunoreactivity can theoretically be derived by plasmin cleavage of fibrinogen or fibrin I but not of fibrin II (which contains neither FPA nor FPB) because plasmin is known to cleave the bond between arginine $(\mathrm{B} \beta 42)$ and alanine (B $\beta 43)$ (4). Incubation of streptokinase with plasma produced TIFPB immunoreactivity that eluted similarly to B $\beta 1-42$ on Sephadex G-50 (Figs. 2 and 3D). These facts make it likely that plasmin cleavage of the bond linking arginine $(\mathrm{B} \beta 42)$ and

TABLE II

In Vitro Generation Rate of FPA

\begin{tabular}{rc}
\hline Patient & In vitro FPA generation rate \\
\hline & $p m o l / m l$ \\
1 & 1.2 \\
2 & 6.3 \\
3 & 3.6 \\
4 & 1.1 \\
5 & 3.5 \\
6 & 6.9 \\
7 & 0 \\
8 & 0 \\
9 & 0.5 \\
10 & 0
\end{tabular}

alanine (B $\beta 43)$ is responsible for the TIFPB immunoreactivity found in patients' plasma although it is conceivable that leukocyte proteases (27) or other enzymes might also cleave FPB containing peptides under appropriate circumstances. TIFPB immunoreactivity was generated much more rapidly when streptokinase was incubated with reptilase-treated plasma than with control plasma (Fig. 2) indicating that fibrin I is preferred over fibrinogen as a substrate for plasmin. This phenomenon is an extension of the well-recognized observation that plasmin proteolyzes fibrin more readily than fibrinogen (28). Recent work has shown that plasminogen binds to fibrin via lysinebinding sites. It has been suggested that plasmin binds to fibrin and not to fibrinogen and that the bound plasmin is protected from inhibition by the $\alpha_{2}$-plasmin inhibitor (29). This could explain why plasmin cleaves $\mathrm{B} \beta$ 1-42 from fibrin I more readily than from fibrinogen.

Based on the above considerations, the pattern of changes shown in Figs. 5 and 6 is interpreted as follows. Within minutes of infusion of saline, thrombin is formed which cleaves fibrinogen to produce FPA and fibrin I and releases $\beta$ TG and PF4 from platelets. Thrombin activity reaches its highest level between 1 and $2 \mathrm{~h}$, has decreased at $4 \mathrm{~h}$, and is normal at 24 and $48 \mathrm{~h}$. Plasmin action starts after thrombin action with the production of TIFPB implying formation of fragment $X(4-8)$. Because the data shown in Fig. 2 indicate that fibrin $I$ is preferred to fibrinogen as a substrate for plasmin it is likely that the major source of TIFPB immunoreactivity is fibrin $\mathrm{I}$. $\mathrm{NH}_{2}$-terminal $\mathrm{B} \beta$ chain cleavage (reflecting fragment $\mathrm{X}$ formation) precedes the formation of fragment $Y$, which in turn precedes the generation of fragments $\mathrm{D}$ and $\mathrm{E}(4-8)$ and it is the latter fragments (Y, D, and $\mathrm{E})$, which are measured in the FDP assay. One would, therefore, anticipate that $B \beta 1-42$ levels would rise earlier than FDP levels and the data shown in Fig. 5 suggest but do not prove this. More detailed studies over the $2 \mathrm{nd} h$ and more sensitive assays for FDP will be required. FDP levels declined more slowly than the TIFPB levels presumably both because of slower plasma clearance of the larger molecules and of continued lysis of fibrin. The slow clearance of FDP results in the 24 -h pattern in which maximum reduction in fibrinogen levels is present while FDP levels are still high. Low fibrinogen and high FDP levels form the principal laboratory criteria for disseminated intravascular coagulation $(30,31)$, yet at $24 \mathrm{~h}$ thrombin action as reflected by FPA levels was virtually normal. This distinction in the time sequence between thrombin action in vivo and the principal laboratory criteria for diagnosing disseminated intravascular coagulation may be part of the explanation for the contradictory results of heparin therapy. If a similar sequence of proteolyses occurs in clinical disseminated intravascular coagulation, one 
would anticipate that heparin would be useful only when thrombin action is significantly increased and not when it is normal.

The rapid in vitro FPA generation in the peripheral blood of 6 of 10 patients $1 \mathrm{~h}$ after injection of saline indicates the presence of thrombin activity in the blood sample (23) implying systemic dilution of thrombin or of activated factors that were initially formed in the uterus. Similarly increased thrombin activity was found in the peripheral blood of a patient with a localized hemangioma in whom prothrombin activation almost certainly starts in the hemangioma (23).

In vitro studies showed that addition of thrombin to citrated platelet-rich plasma or to whole blood resulted in FPA cleavage at thrombin concentrations 100 -fold less than were required to release $\beta T G$ and PF4 (15) but in spontaneously clotting blood FPA cleavage and $\beta$ TG and PF4 release occurred in parallel (11). The data in the present study more closely resemble the pattern occurring in spontaneously clotting whole blood. The difference in the magnitude of the changes in the plasma concentrations of $\beta \mathrm{TG}$ and PF 4 may be caused by differences in the plasma clearance rate of the two proteins. It is not clear why the platelet count continued to decline between 24 and $48 \mathrm{~h}$ despite normal $\beta$ TG and PF4 levels and a rising fibrinogen level.

Aside from the practical implications concerning disseminated intravascular coagulation the data also suggest a theory relating the proteolysis of fibrinogen by thrombin and plasmin in vivo. The theory is illustrated in Fig. 7. Thrombin initially cleaves fibrinogen to produce free FPA and fibrin I, which polymerizes to form a visible clot. Thrombin then cleaves fibrin I to yield free FPB and fibrin II. If plasmin rather than thrombin cleaves the $\mathrm{B} \beta$ chain on fibrin $\mathrm{I}, \mathrm{B} \beta 1-42$ and fragment $X$ result. The data in Fig. 2 indicate that plasmin removes $\mathrm{B} \beta 1-42$ much more rapidly from fibrin I than from fibrinogen. There are no data as yet concerning the influence of polymerization on the rate of plasmin cleavage of the arginine $(\mathrm{B} \beta 42)$-alanine (B $\beta 43)$ bond. However, there is evidence that polymerization is important for thrombin to release FPB from fibrin I (1). Fibrin II forms thicker strands than fibrin I (32) and may be more likely to result in occlusive thrombosis. The formation by plasmin of fragment $\mathrm{X}$ from fibrin $\mathrm{I}$ serves as a mechanism to regulate fibrin II formation. It is suggested that the changes in fibrinogen after intrauterine infusion of saline and in the clinical syndrome of disseminated intravascular coagulation represent the effects of a defense mechanism for coping with thrombin generated in the blood as a response to injury. Thrombin produces fibrin $I$, which is principally converted to fragment $\mathrm{X}$, thus limiting fibrin II formation and consequent intravascular occlusion by thrombus.

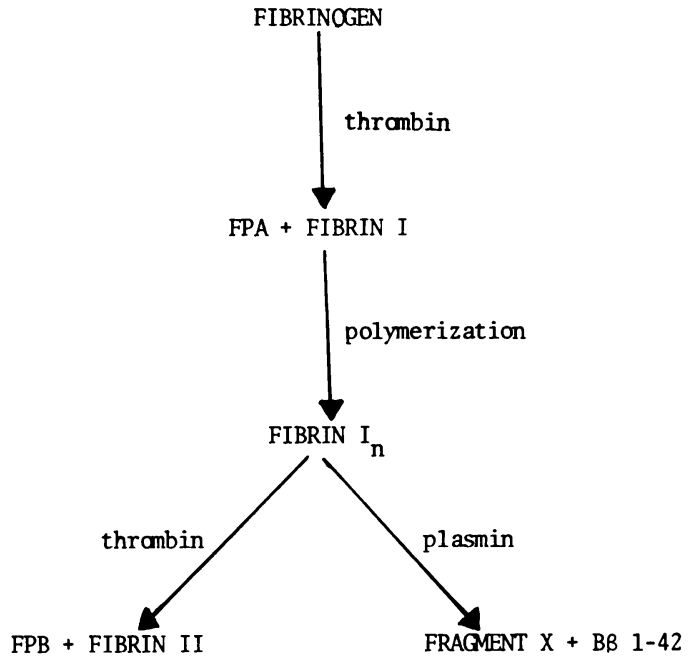

FIGURE 7 Theory depicting fibrinogen proteolysis by thrombin and plasmin. Studies by Blombäck et al. (1) indicate that polymerization of fibrin $I$ is important for removal of FPB. Data in the present paper indicate that plasmin cleaves $\mathrm{B} \beta 1$ 42 from fibrin I preferentially over fibrinogen. The influence of polymerization of fibrin I on the rate of plasmin-induced removal of $B \beta 1-42$ is not yet known.

\section{ACKNOWLEDGMENTS}

We would like to thank Carol Wilkins, Michael Drillings, and George Lesznik for excellent technical assistance.

The work was supported by research grants from the National Institutes of Health (HL-15486, HL-15596 \& HL21006).

\section{REFERENCES}

1. Blombäck, B., B. Hessel, D. Hogg, and L. Therkildsen. 1978. A two-step fibrinogen-fibrin transition in blood coagulation. Nature (Lond.). 275: 501-505.

2. Blombäck, B., and A. Vestermark. 1958. Isolation of fibrinopeptides by chromatography. Ark. Kemi. 12: $173-182$.

3. Bilezikian, S. B., H. L. Nossel, V. P. Butler, Jr., and R. E. Canfield. 1975. Radioimmunoassay of fibrinopeptide B and kinetics of fibrinopeptide cleavage by different enzymes. J. Clin. Invest. 56: 438-445.

4. Takagi, T., and R. F. Doolittle. 1975. Amino acid sequence studies on plasmin-derived fragments of human fibrinogen: amino-terminal sequences of intermediate and terminal fragments. Biochemistry. 14: 940-946.

5. Mosesson, M. W., J. S. Finlayson, R. A. Umfleet, and D. Galanakis. 1972. Human fibrinogen heterogeneities. I. Structural and related studies of plasma fibrinogens which are high solubility catabolic intermediates. J. Biol. Chem. 247: 5210-5219.

6. Marder, V. J., N. R. Shulman and W. R. Carroll. 1969. High molecular weight derivatives of human fibrinogen produced by plasmin. I. Physicochemical and immunological characterization. J. Biol. Chem. 244: 2111-2119.

7. Budzynski, A. Z., V. J. Marder, and J. R. Shainoff. 1974. Structure of plasmic degradation products of fibrinogen. J. Biol. Chem. 249: 2294-2302.

8. Pizzo, S. V., M. L. Schwartz, R. L. Hill and P. A. McKee. 
1972. The effect of plasmin on the subunit structure of human fibrinogen. J. Biol. Chem. 247: 636-645.

9. Witte, L. D., K. L. Kaplan, H. L. Nossel, B. A. Lages, H. J. Weiss, and D. S. Goodman. 1978. Studies of the release from human platelets of the growth factor for cultured human arterial smooth muscle cells. Circ. Res. 42: 402-409.

10. Niewiarowski, S., and D. P. Thomas. 1969. Platelet factor 4 and adenosine diphosphate release during human platelet aggregation. Nature (Lond.). 222: 1269-1270.

11. Kaplan, K. L. 1978. Proteins secreted by platelets: significance in detecting thrombosis In Thrombosis: Animal \& Clinical Models. H. J. Day editor. Plenum Publishing Corp., New York. 105-120.

12. Nossel, H. L., I. Yudelman, R. E. Canfield, V. P. Butler, Jr., K. Spanondis, G. D. Wilner, and G. D. Qureshi. 1974. Measurement of fibrinopeptide A in human blood.J. Clin. Invest. 54: 43-53.

13. Bolton, A. E., C. A. Ludlam, D. S. Pepper, S. Moore, and J. D. Cash. 1976. A radioimmunoassay for platelet factor 4. Thromb. Res. 8: 51-58.

14. Handin, R. I., M. McDonough, and M. Lesch. 1978. Elevation of platelet factor 4 in acute myocardial infarction-measurement by radioimmunoassay. J. Lab. Clin. Med. 91: 340-350.

15. Kaplan, K. L., H. L. Nossel, M. Drillings, and G. Lesznik. 1978. Radioimmunoassay of platelet factor 4 and $\beta$ thromboglobulin: development and application to studies of platelet release in relation to fibrinopeptide A generation. Br. J. Haematol. 39: 129-146.

16. Ludlam, C. A., S. Moore, A. E. Bolton, D. S. Pepper, and J. D. Cash. 1975. The release of a human platelet specific protein measured by a radioimmunoassay. Thromb. Res. 6: $543-548$.

17. Stander, R. W., H. C. Flessa, H. I. Glueck, and C. T. Kisker. 1971. Changes in maternal coagulation factors after intra-amniotic injection of hypertonic saline. Obstet. Gynecol. 37: 660-666.

18. Weiss, A. E., W. E. Easterling, Jr., M. H. Odom, C. W. McMillan, A. M. Johnson, and L. M. Talbert. 1972. Defibrination syndrome after intra-amniotic infusion of hypertonic saline. Am. J. Obstet. Gynecol. 113: 868-876.

19. Schwartz, R. S., W. Greston, and G. J. Kleiner. 1972. Defibrination in saline abortion. Obstet. Gynecol. 40: $728-737$.
20. Van Royen, E. A., P. E. Treffers, and J. W. Ten Cate. 1974. Hypertonic saline induced abortion as pathophysiologic model of low grade intravascular coagulation. Scand. J. Haemat. 13: 166-174.

21. Blombäck, B., M. Blombäck, P. Edman, and B. Hessel. 1966. Human fibrinopeptides. Isolation, characterization and structure. Biochem. Biophys. Acta. 115: 371-396.

22. Nossel, H. L., L. R. Younger, G. D. Wilner, T. Procupez R. E. Canfield, and V. P. Butler, Jr. 1971. Radioimmunoassay of human fibrinopeptide A. Proc. Natl. Acad. Sci. U. S. A. 68: 2350-2353.

23. Nossel, H. L., M. Ti, K. L. Kaplan, K. Spanondis, T. Soland, and V. P. Butler, Jr. 1976. The generation of fibrinopeptide $\mathrm{A}$ in clinical blood samples. Evidence for thrombin activity. J. Clin. Invest. 58: 1136-1144.

24. Merskey, C., P. Lalezari, and A. J. Johnson. 1969. A rapid, simple sensitive method for measuring fibrinolytic split in products in human serum. Proc. Soc. Exp. Biol. Med. 131: 871-875.

25. Ellis, B. C., and A. Stransky. 1961. A quick and accurate method for the determination of fibrinogen in plasma. J. Lab. Clin. Med. 58: 477-488.

26. Iwanaga, S., P. Wallen, N. Gröndahl, A. Henschen, and B. Blombäck. 1969. On the primary structure of human fibrinogen: isolation and characterization of $N$-terminal fragments from plasmic digests. Eur. J. Biochem. 8: 189-199.

27. Bilezikian, S. B., and H. L. Nossel. 1977. Unique pattern of fibrinogen cleavage by human leukocyte proteases. Blood. 50: 21-28.

28. Alkjaersig, N., A. P. Fletcher, and S. Sherry. 1959. The mechanism of clot dissolution by plasmin.J. Clin. Invest. 38: 1086-1095.

29. Wiman, B., and D. Collen. 1978. Molecular mechanism of physiological fibrinolysis. Nature (Lond.). 272: 549-550.

30. Merskey, C., A. J. Johnson, G. E. Kleiner, and H. Wohl. 1967. The defibrination syndrome: clinical features \& laboratory diagnosis. Br. J. Haematol. 13: 528-549.

31. Minna, J. D., S. J. Robboy, and R. W. Colman. 1974. Disseminated Intravascular Coagulation in Man. Charles C Thomas, Springfield, Ill.

32. Laurent, T. C., and B. Blombäck. 1959. On the significance of the release of two different peptides from fibrinogen during clotting. Acta Chem. Scand. 12: 1875-1877. 